explores the current international job market in gerontology and the competencies required as identified in job postings.

\section{THE ASSOCIATION OF GERONTOLOGY IN HIGHER EDUCATION (AGHE) GERONTOLOGY EDUCATION COMPETENCIES}

J.C. Frank, J.D. Damron-Rodriguez, University of

California, Los Angeles, Los Angeles, California

The Association of Gerontology in Higher Education (AGHE) is a global leader in education on aging and has revitalized competencies for gerontology education programs at the Associate, Bachelor's and Master's degree levels over a 3-year iterative process. This presentation will review the consensus-building process that used a tiered "circle of influence" method, the foundations and organization of the competencies, and the final set of AGHE gerontology education competencies. This presentation will include examples of utilizing the competencies for curricula development, application of a newly designed curriculum mapping tool and approaches to competency-based outcome evaluation. Discussion will include how the AGHE competencies are now being integrated into the Accreditation of Gerontology Education Council as one international program review criterion for programmatic accreditation of gerontology education programs.

\section{COMPETENCIES IN EUROPEAN GERONTOLOGICAL HIGHER EDUCATION. AN EXPLORATIVE STUDY ON CORE ELEMENTS}

E. Schoenmakers ${ }^{1}$, J.D. Damron-Rodriguez ${ }^{2}$, J.C. Frank ${ }^{2}$, B. Pianosi ${ }^{3}$, J. Jukema ${ }^{4}, 1$. Applied Gerontology, Fontys University of Applied Sciences, Berkel-Enschot, Netherlands, 2. UCLA, Los Angeles, California, 3. Huntington University, Sudbury, Ontario, Canada, 4. Windesheim University of Applied Sciences, Zwolle, Netherlands

This study explores whether there is a common core of competencies in European gerontology education programs by doing a cross-comparison of five undergraduate level programs. Content analysis of competency profile documents at the five European educational programs were studied using thematic analysis. Study results document that there indeed is a common core of elements in gerontological educational programs. Three clusters which included a total of fifteen categories were identified. The clusters were labeled professional attitude, communication skills and service provision. Clusters and categories varied across the five programs. One program in particular included less clusters and categories. This may reflect a difference in focus in the program, but could also reflect a less elaborately formulated competency profile document. The results of this study show that, at the level of formulating competencies, there is a strong agreement on the major components that are important for a gerontologist at the undergraduate level.

\section{IMPROVING LEADERSHIP COMPETENCIES IN PUBLIC HEALTH AND AGING: THE LATIN AMERICA EXPERIENCE \\ E. Vega ${ }^{1}$, J. Parodi ${ }^{2}$, J. Menendez ${ }^{3}$, L. Rodriguez ${ }^{4}$, 1. Life \\ Course, Pan American Health Organization (PAHO),}

Washington, District of Columbia, 2. University of San Martin de Porres, Lima, Peru, 3. Centro Colaborador OPSOMS en Salud Publica y Envejecimiento, La Habana, Cuba, 4. ALMA, La Habana, Cuba

This study evaluates the certificate program "The Specialization in Management of Health Programs for Older Persons". Under the coordination of Pan American Health Organization (PAHO) and the World Health Organization (WHO), several academic institutions in the America's Region developed a competency-based program to respond to the need for increased skills, knowledge and abilities in public health and aging. After nine generations and more than 250 graduates participating in the 10 month virtual education certificate, results indicated positive outcomes and areas for program improvement. Analyses included change levels using the Kirkpatrick model (reaction, learning, behavior / transfer and impact / outcome). The results provide an opportunity to refine and improve the model initially utilized to foster potential country implementation and to promote the scaling up of the Specialization certificate program and training experience.

\section{COMPETENCIES INCLUDED IN GERONTOLOGY JOB POSTINGS: AN INTERNATIONAL COMPARISON}

\section{B. Pianosi, Gerontology, Huntington University, Sudbury,} Ontario, Canada

As society is ageing, experts from a wide range of professions will work with and for older adults. Some of these professionals are specifically trained to work with older adults, some have a different training with a specialization in older adults or ageing, while others have an occupational training without specific competencies in gerontology. This is true for most industrialized countries, including those located in Europe and North America.

In this study, the job market in the field of gerontology is explored internationally and the competencies as described in the job postings are identified.

\section{SESSION 4745 (SYMPOSIUM)}

\section{THE CONSEQUENCES OF GENTRIFICATION AND DISPLACEMENT FOR OLDER ADULTS IN THE U.S.} Chair: A.J. Lehning, University of Maryland, Baltimore, Maryland

Discussant: A. DeLaTorre, Portland State University, Portland, Oregon

A major focus of U.S. aging policies and programs is supporting the ability of older adults to age in place, based on evidence that neighborhoods become increasingly important in later life due to place attachment and the belief that aging in place can lead to optimal health and well-being. Gentrification, which occurs when more affluent residents move into a neighborhood that was previously occupied by lower-income residents, has received limited attention in gerontological scholarship. The percent of neighborhoods experiencing gentrification has increased in the U.S., and therefore the ramifications of gentrification are receiving more attention from policymakers, researchers, and the media, yet the potential repercussions for older adults are often ignored. To address this gap, this symposium will 